\title{
工商管理中的热点问题分析及发展趋势
}

\author{
韦 涁
}

临沂市河东区行政审批服务局，山东 临沂 276000

[摘要]在最近的几年时间里, 我国社会经济水平得到了显著的提升, 从而推动了各个行业的稳步发展, 为我国工商管理相关 研究工作的开展创造了良好的条件。就现如今我国工商管理实际情况来说，与其他发达国家的整体水平还存在明显的差距， 所以我们需要综合自身各方面实际情况来对其他国家成功经验进行借鉴，从而推动工商管理行业的稳步健康发展。为了促使 工程管理工作能够在企业发展中发挥出积极的影响作用, 推动企业朝着现代化、规模化的方向迈进, 我们需要拥有足够的专 业工商管理团队，并且要对工商管理热点问题以及未来发展形式进行综合深入的研究。

[关键词]工商管理; 发展战略; 企业文化

DOI: $10.33142 /$ mem.v1i3.2565 中图分类号: F272 文献标识码：A

\section{Analysis and Development Trend of Hot Issues in Business Administration}

\author{
WEI Bin
}

Linyi Hedong Municipal Bureau of Administrative Examination and Approval Service, Linyi, Shandong, 276000, China

\begin{abstract}
In recent years, Chinese social and economic level has been significantly improved, which promotes the steady development of various industries and creates good conditions for development of Chinese business management related research work. As far as the actual situation of Chinese business administration is concerned, there is still an obvious gap with the overall level of other developed countries. Therefore, we need to integrate our own actual situation to learn from the successful experience of other countries, so as to promote the steady and healthy development of industry and business administration industry. In order to promote engineering management to play a positive role in the development of enterprises and promote enterprises to move towards modernization and scale, we need to have enough professional business administration teams and should conduct comprehensive and in-depth research on hot issues of business administration and future development forms.
\end{abstract}

Keywords: business administration; development strategy; corporate culture

引言

工商管理具有较强的复杂性, 其涉及到管理科学技术、工程技术等多个领域, 具有较强的实践性。在制定工商管 理工作目标的时候, 应当将最先进的工商管理理念加以运用, 不断提升工商管理工作的整体水平, 将工商管理工作的 作用充分的发挥出来。

1 工商管理的主要热点问题

1.1 企业发展战略管理工作的研究

就企业的发展形势来说, 高效的发展规划能够对企业发展起到良好的辅助作用。企业在运营发展过程中, 往往需 要遇到各种问题, 所以企业应当对可能遇到的问题加以预判, 针对性的制定预防和解决方案。如果企业对于自身发展 战略缺少重视, 而只是对当前管理工作中所存在的问题加以解决, 那么对于企业的稳步发展是非常不利的, 并且也无 法满足社会经济发展的需要 ${ }^{[1]}$ 。

1.2 企业文化管理工作的研究

因为受到以往老旧模式的运营管理模式的限制, 部分企业对于企业文化这种在企业发展中影响较小的方面缺少基 本的重视。但是在社会快速发展的过程中, 人们的思想也发生了明显的裱花, 企业对于管理机制的调整以及创新工作 方面的研究投入了更多的精力, 企业文化逐渐的转变成为了企业的主要研究对象。综合我国传统文化以及企业发展价 值观来实施综合性的研究, 企业运营过程中对企业文化的创建工作在工商管理工作中也是一项重点工作, 企业在落实 文化建设工作的时候, 往往都会将企业发展理念、企业社会形象以及企业发展目标进行结合, 从而从整体上对企业运 营加以管控，这样对于企业在整个行业竞争中保持良好的综合实力能够起到积极的辅助作用 ${ }^{[2]}$ 。

1.3 企业人力资源管理工作的研究

企业的良好发展是不能脱离企业员工工作的开展的, 并且人力资源在企业发展中的作用是非常重要的。加大力度 对企业人力资源进行综合管理和整合是确保企业稳定健康发展的基础。人力资源的价值逐渐转变成为了企业发展的重 要基础, 企业务必要利用有效的方式方法来将员工的价值充分的发挥出来, 并且企业需要对员工工作积极性加以有效 
的调动, 并且要尽可能的为员工创造良好的工作环境。企业要综合各方面实际情况来创设企业运营激励机制, 确保员 工工作积极性能够始终保持在最佳的状态, 这样对于企业的良好发展也可以起到良好的作用。现如今我国企业人力资 源管理工作所侧重的是创设激励机制、调查员工满意度, 企业薪资结构设计等多项工作。在社会经济粉丝发展以及科 学技术水平不断提升的带动下, 企业的管理模式以及运营模式都发生了巨大的变化, 这样也为人力资源管理工作添加 了诸多的新的研究内容 ${ }^{[3]}$ 。

\section{2 改进工商管理活动方法}

\section{1 健全管理制度}

就企业来说, 要想将工商管理工作的作用充分的施展出来, 那么最为重要的就是需要制定针对性的管理制度。换 句话说就是, 良好的管理制度能够促进企业稳定健康发展。如果缺少健全的管理制度的保障, 那么必然会导致管理工 作丧失其基本的作用。就现如今实际情况来说, 部分企业管理工作存在失控的情况, 这主要是因为制度的不健全所造 成的, 如果制度存在不切使用或者是不完善的情况, 那么管理工作是无法保证其规范性的。针对这个问题, 企业务必 要对工作的重点进行合理的调控, 要重视管理制度的创设。在制定管理制度的时候, 工作人员需要遵从一定的规律, 先制定一个整体框架, 随后对内容进行细分, 这样才能确保制度具有良好的完整性和可信性 ${ }^{[4]}$ 。

\section{2 重视引导、管理工作}

首先, 管理部门工作人员务必要充分结合现实情况, 对市场发展情况进行全面的了解和掌握, 这样才能为后期制 定企业发展方案提供有力的支持。其次, 管理部门需要借助恰当的方式方法, 在拥有良好的理论依据的基础上, 还需 要提升制度的综合性能, 为企业开展各项工作给予规范性的指导。最后, 企业从各个细节入手进行全面的管控, 避免 发生危险事故。

\section{3 工商管理发展趋势}

\section{1 知识管理上升成为企业的核心管理}

企业知识管理工作其实质就是说企业借助各种有效的方式方法来提升各类资源的利用效率, 推动企业稳定持续健 康发展, 并且调动员工工作积极性。其次, 要提升知识的共享范围, 利用最先进的信息技术, 在综合当代管理方式方 法的基础上, 全面推进管理工作的落实。再有, 要在知识经济快速发展的形势下, 企业在落实工商管理工作的过程中, 需要对知识管理工作给予重点关注, 知识管理在工商管理工作中所起到的作用也是非常重要的, 切实的落实知识管理 工作，不但可以提升资源的利用效率，并且还可以增强企业自身的综合实力，推动企业稳定健康的发展 ${ }^{[5]}$ 。

\section{2 学习型企业建设备受关注}

首先, 需要对各项规范进行全面的了解。就以往企业开展工程管理工作来说, 企业只要保证遵从行政机构以及地 方政府制定的相关法律条款就可以保证稳定的发展, 并且取得良好的经济收益。而学习型企业需要在严格按照法律法 规落实各项工作的前提下, 还需要创设完善的企业文化, 推动企业发展能够与市场经济发展相统一。其次, 针对企业 价值观念加以正确的理解。以往工商管理工作的核心目标就是保证企业获得更多的经济收益, 在整个行业中占据不败 的境地, 而学习型企业要在不断扩展收益的基础上, 还需要树立良好的社会责任意识, 全面的为社会发展提供服务。 最后, 综合企业各方面实际情况, 为学生发展制定全新的目标。传统工商管理工作都是以企业良好发展为目标, 而在 社会不断发展的影响下, 企业应当充分的担负社会职责, 为民众提供更多的就业机会, 促使企业在发展的同时, 以解 决社会问题为发展目标，使工商管理得到升华。

\section{3 国际化管理水平的提升}

在世界经济全球化的大前提下企业要想取得更大的发展空间, 就必须学会与国际上的企业进行接轨, 以此来提高 企业的整体层次。在保证自身发展的基础上提升发展的国际化水准, 将作为工商管理发展的一个重要趋势, 企业想要 在国际上进行深层次的发展, 提升国际化管理水平, 必须以自身的发展战略作为基石, 不断改进企业原有的经营理念 和方法。

\section{4 结束语}

综合以上阐述我们总结出, 在社会经济飞速发展的带动下, 企业工商管理工作越发的受到了人们的关注, 这样不 仅为企业发展提供了机会, 也带来了一定的挑战, 所以相关部门务必要正确的对待自身的问题, 全面的落实工商管理 工作。详细的来说, 企业要关注战略、人力、文化等多个方面的管理, 一步步提升员工素质, 为企业运行注入不竭动 力。同时, 要看到他人的优势, 善于学习, 并与自身情况相结合, 实现管理手段、模式的创新, 促进企业进一步发展。

\section{[参考文献]}

[1]徐媛, 杜晶晶.工商管理的热点问题及发展趋势探析 $[\mathrm{J}]$. 农村经济与科技, 2019, 30(24): 135-136.

[2]芶千迎.工商管理的热点问题分析与探讨 [J]. 商讯,2019 (26) : 149-151.

[3] 邓跃.浅谈工商管理的热点问题及发展趋势 [J]. 现代经济信息, 2017(04): 144.

[4]王伟.工商管理的热点问题及发展趋势探析 $[J]$. 经济研究导刊, 2017(04): 181 .

[5]史慧恩, 张群, 李群霞. 国内外工商管理现状比较及发展建议 [J].中国科技论坛, 2007 (09) : 125-130.

作者简介: 韦涁 (1976.10.17-), 女, 毕业院校: 中共山东省委党校, 所学专业: 法律, 当前就职单位: 临沂市河东 区行政审批服务局，职务：科长，职称级别：中级经济师（工商管理）。 